\title{
Global Cloud-Resolving Models
}

\section{Masaki Satoh $^{1}$ (D) Bjorn Stevens ${ }^{2}$ (D) $\cdot$ Falko Judt $^{3}$ (D) $\cdot$ Marat Khairoutdinov $^{4} \cdot$ Shian-Jiann Lin $^{5} \cdot$ William M. Putman $^{6}$. Peter Düben ${ }^{7}$}

Published online: 17 May 2019

(C) The Author(s) 2019

\begin{abstract}
Purpose of Review Global cloud-resolving models (GCRMs) are a new type of atmospheric model which resolve nonhydrostatic accelerations globally with kilometer-scale resolution. This review explains what distinguishes GCRMs from other types of models, the problems they solve, and the questions their more commonplace use is raising.

Recent Findings GCRMs require high-resolution discretization over the sphere but can differ in many other respects. They are beginning to be used as a main stream research tool. The first GCRM intercomparison studies are being coordinated, raising new questions as to how best to exploit their advantages.

Summary GCRMs are designed to resolve the multiscale nature of moist convection in the global dynamics context, without using cumulus parameterization. Clouds are simulated with cloud microphysical schemes in ways more comparable to observations. Because they do not suffer from ambiguity arising from cumulus parameterization, as computational resources increase, GCRMs are the promise of a new generation of global weather and climate simulations.
\end{abstract}

Keywords Global cloud-resolving model · Cloud microphysics scheme · Cumulus parameterization · Deep convection · Convective aggregation $\cdot$ Multiscale structure

\section{Introduction}

Global cloud-resolving models (GCRMs) are a new category of atmospheric global models designed to solve different flavors of the nonhydrostatic equations through the use of kilometer-scale global meshes. GCRMs make it possible to explicitly simulate deep convection, thereby avoiding the need for cumulus parameterization and allowing for clouds to be "resolved" by microphysical models responding to grid-scale forcing. GCRMs require high-resolution discretization over the globe, for which a variety of mesh structures have been proposed and employed. The first

This article is part of the Topical Collection on Convection and Climate

Masaki Satoh

satoh@aori.u-tokyo.ac.jp

1 Atmosphere and Ocean Research Institute, The University of Tokyo, 5-1-5 Kashiwanoha, Kashiwa, Chiba 277-8564, Japan

2 Max Planck Institute for Meteorology, Bundesstrae 53, Hamburg 20255, Germany

3 National Center for Atmospheric Research, P.O. Box 3000, Boulder, CO 80307-3000, USA
GCRM was constructed 15 years ago [1], and in recent years, other groups have also begun adopting this approach, enabling the first intercomparison studies of such models. Because conventional general circulation models (GCMs) suffer from large biases associated with cumulus parameterization (e.g., [2]), GCRMs are attractive tools for researchers studying global weather and climate. In this review, GCRMs are described, with some emphasis on their historical development and the associated literature documenting their use. The advantages of GCRMs are presented, and currently existing GCRMs are listed and described. Future prospects for GCRMs are also presented in the final section.

4 School of Marine and Atmospheric Sciences, Stony Brook University, Stony Brook, NY 11794-5000, USA

5 Geophysical Fluid Dynamics Laboratory, Princeton University, Forrestal Campus/U.S. Route 1, P.O. Box 308, Princeton, NJ 08542, USA

6 NASA Global Modeling and Assimilation Office, Goddard Space Flight Center, Greenbelt, MD 20771, USA

7 European Centre for Medium-Range Weather Forecasts, Shinfield Road, Reading RG2 9AX, UK 


\section{What Is in a Name?}

The term "Cloud-Resolving Model" or CRM, a term that emerged in the late 1980s (e.g., [3]) and which became popularized through the strategy proposed by the GEWEX Cloud System Study [4-6], is loosely used to refer to models to study the statistical properties of cloud systems. The initialism C-R-M is often used synonymously with the phrases "cumulus ensemble model"-a phrase which predates it $[7,8]$ —or "cloud system resolving model," phrases introduced with the aim of distinguishing models designed to study the statistics of clouds, from models developed to study the transient dynamics of a single cloud.

No consensus has emerged as to the resolution at which a model can be considered cloud-resolving, but typical gridresolutions are informed by early studies with a (single) cloud model and which suggest that models with grid spacings of about $1 \mathrm{~km}$ begin to resolve many important features of convection. For instance, [9] used the mesh size of $100 \mathrm{~m}$ in the horizontal and vertical directions, to simulate a cloud bubble; likewise, [10] used $1 \mathrm{~km}$ horizontal spacing to study convective bubbles in three dimensions. Later, [11] chose $1 \mathrm{~km}$ for the horizontal and $500 \mathrm{~m}$ for the vertical grid intervals for simulations of convective storms and hence cloud systems. Early cloud-scale models in cloud physics research have used similar range of the resolutions: [12] chose $3.2 \mathrm{~km}$ for the horizontal and $0.7 \mathrm{~km}$ for the vertical grid intervals; [13] used $0.6 \mathrm{~km}$ for the horizontal and $0.25 \mathrm{~km}$ for the vertical grid intervals at the finest; and [14] set $0.375 \mathrm{~km}$ for the horizontal and $0.25 \mathrm{~m}$ for the vertical grid intervals. Later studies, involving more systematic comparisons of different resolutions (e.g., [15-17]), support the kilometer-scale premise of these early studies.

An important step forward in the evolution of cloudresolving models took place in the late 1980s and 1990s when increasing computational resources made it possible to simulate larger domains (in three-dimensional configuration with several hundreds of kilometers) and longer integration periods (with several days) and thereby supplement idealized simulations of individual clouds and cloud ensembles by simulations of observed events, forced by field observations over realistically configured domains [18-21]. This approach was especially important for, and gained momentum from, the GEWEX Cloud Systems Studies framework [6].

The ability to simulate over larger domains without compromising on resolution also emboldened idealized studies over longer periods of times. Examples of the application of CRMs for this purpose included their use for radiativeconvective equilibrium (RCE) simulations, first in two dimensions with a mesh of $1 \mathrm{~km} \mathrm{[22]} \mathrm{and} \mathrm{later} \mathrm{in} \mathrm{three} \mathrm{dimensions}$ with a somewhat coarser (3 km) mesh [23]. More recent studies of RCE have used even larger domains, but the typical grid spacing has remained surprisingly constant — consider that the recent RCE Model Intercomparison Project (RCEMIP) suggests the use of $1-3 \mathrm{~km}$ for the horizontal grid interval [24].
As many people are eager to point out, cloud-resolving models do not resolve all clouds. In reality, clouds have a detailed multiscale structure and a complicated morphology colored by a variety of cloud microphysics characteristics (phase, size distribution, shape, etc.). This makes it difficult to characterize them as resolved by most CRMs, as even for important cloud systems, large-eddy simulations (LES), with mesh size of 10-100 m, are not enough. Direct numerical simulations (DNS), which are starting to become feasible for some cloud studies [25], suggest that Reynolds number similarity provides statistical convergence at a resolution of about $0.5 \mathrm{~m}$ [26], for adequately representing mixing at cloud boundaries [27]. This is a factor of 100 coarser than would be required to resolve scales down to the Kolmogorov scale but still far out of reach on larger domains, even for most idealized studies.

Technically, CRMs can be thought of as a more evocative way to describe nonhydrostatic equation solvers, which calculate the buoyancy acceleration associated with convective clouds. Because the nonhydrostatic regimes become important with a mesh size less than about $5 \mathrm{~km} \mathrm{[15],} \mathrm{which} \mathrm{also} \mathrm{happens} \mathrm{to} \mathrm{be}$ the scale required to resolve convective circulations (deep precipitating clouds) whose scale is commensurate with the scale of the troposphere $(10-15 \mathrm{~km})$, this often sets a basic scale for a CRM and the fact that such models, almost by construction, forgo the parameterization of deep convection. Hence, what a CRM really resolves is less the cloud and more the mesoscale dynamics of precipitating storm systems, which is why in recent studies (e.g., [28, 29]), the term storm-resolving model (SRM) is sometimes used as a substitute for CRM. Stevens et al. [30], for instance, chose the term "global storm-resolving model" (GSRM) to refer to SRM over the global domain instead of GCRM. The term "convection-permitting model" is also frequently used to denote the above type of the models.

Although GCRM generally refers to a global nonhydrostatic model with mesh size less than about $5 \mathrm{~km}$, and thereby forgoing the use of cumulus parameterization, some exceptions to this rule are noteworthy. For instance, on scales of a few kilometers, some groups continue to report satisfactory results when integrating the hydrostatic equations, and other groups are reluctant to forgo the use of cumulus parameterization entirely. Looking toward the future, and yet finer resolution, simulations with a GCRM using a sub-kilometer $(870 \mathrm{~m})$ mesh for a period of 2 days have been performed [31]. Global LES simulations for a period of a few hours and with an $\mathrm{O}(100 \mathrm{~m})$ numerical mesh are thus becoming conceivable and the first such simulations may be realized in the next few years.

\section{History of GCRMs}

From a certain perspective, GCRMs are just global extensions of commonly used nonhydrostatic models as have long been implemented in regional domains. Yet, because of the complexity 
of the grid configuration for the spherical geometry [32,33], and the computational expense they imply, GCRMs require considerably more development, both in terms of their formulation and computational implementation, than would be implied by simply increasing the domain of pre-existing models. For this reason, and due to a lack of access to Tier- 0 computational resources, GCRMs remain the remit of a rather limited number of groups, which include developments around: the Nonhydrostatic Icosahedral Atmospheric Model (NICAM) $[1,34,35]$ in Japan, ICOsahedral Nonhydrostatic (ICON) [36, 37] in Germany, the Model for Prediction Across Scales (MPAS) [38], Finite-Volume Dynamical Core on the Cubed Sphere (FV3) [39], the Goddard Earth Observing System Model, Version 5 (GEOS-5) [40], the global version of the System for Atmospheric Modeling (Global SAM) [41] in the USA, and the Integrated Forecast System (IFS) by the European Centre for Medium-Range Weather Forecasts (ECMWF) which is available as a spectral (IFS-ST [42]) and finite-volume model (IFS-FVM [43, 44]). Before the first GCRMs listed above, there was considerable effort toward GCRMs, as described in earlier reviews, e.g., [34, 45, 46].

A variety of paths led to the development of the present stable GCRMs. Both ICON and NICAM were developments which began at the turn of the millennium but followed very different trajectories. NICAM was developed in part as a new model, targeted to run on a dedicated super computer, the Earth Simulator (https://www.jamstec.go.jp/es/en/index.html), and was completed in 2002. The summary of the early development of NICAM can be found in [34, 47-49]. ICON on the other hand was designed with more varied purposes in mind, as it was to replace the dynamical core of the German Weather Service's global forecast system and the Max-PlanckInstitute's Earth System model, which greatly complicated and delayed its development [36, 37, 50]. Whereas NICAM was, at the outset, designed to as a GCRM, ICON was developed as more general-purpose dynamical core, and only through the course of its development did the idea of using it to represent kilometer and finer scales of motion gain traction (e.g., [51]).

In the USA, for a long time, a different strategy was followed. Super-parameterization, which embedded CRMs in traditional coarse resolution global models, endeavored to realize many of the advantages of GCRMs at a fraction of the computational cost of GCRMs [6, 52]. The application of SuperParameterized Global Models was pioneered by the Center for Multiscale Modeling of Atmospheric Processes (CMMAP; [53]; http://kiwi.atmos.colostate.edu/cmmap/index.html) and for many years provided the only effort outside of Japan which sought to explore the advantages of explicitly resolving most convection for the purpose of global modeling.

Only more recently did the NASA group begin exploiting the scalability of the dynamical core of FV3 developed in the mid2000s [39, 54], to configure the Goddard Earth Observing System (GEOS) model as a GCRM. Limited processes studies with GEOS at $3 \mathrm{~km} \mathrm{[40]} \mathrm{and} \mathrm{then} \mathrm{at} 1.5 \mathrm{~km}$ in 2014 provided the groundwork for this development and showed the valueparticularly in support of Observing System Simulation Experiments or OSSEs [55] — of modeling Earth system processes at resolutions approaching those of the modern satellite observing system [56, 57]. Subsequent work with GEOS has covered a range of applications, including tropical cyclones [58], convective gravity waves and the quasi-biennial oscillation [59], orographic gravity waves [60], and global chemistry transport [61].

Most experience in the application of GCRMs has been collected through the application of NICAM to various problems, as it was the first, and for a long time, the only GCRM $[35,62$, 63]. Its first global simulations using the nonhydrostatic equations employed a horizontal $3.5 \mathrm{~km}$ [64] in a 1-week aqua planet configuration. Later, Miura et al. [65] conducted a global simulation with a realistic land-ocean distribution for 1 week, also with a $3.5-\mathrm{km}$ mesh, to study the multiscale evolution of tropical convection in the framework of the Madden-Julian oscillation (MJO). With advances in algorithm efficiency and computational resources, the length of these simulations has increased steadily, and NICAM is increasingly being used for climate studies, to perform even higher resolution simulations with a subkilometer range [31, 66-69]. Experience has demonstrated that even when run at somewhat coarser ( 7 and $14 \mathrm{~km})$ grid scales, NICAM retains many of the advantages found when run at a more traditional GCRM grid spacing.

Experience with NICAM suggests that even at a seemingly too coarse a resolution (7 to $14 \mathrm{~km}$ ), many of the desirable properties of GCRMs already become apparent. For instance, simulations with $3.5,7$, and $14 \mathrm{~km}$ mesh show similar multiscale structure of convective systems embedded in super-cloud clusters or MJOs $[64,65,70]$. Hence, this multiresolution approach is proving to be a popular way to accelerate GCRM studies and enabling the use of NICAM over multi-decadal timescales [71-73], for larger ensemble simulations $[74,75]$, for collaborative studies with Earth observations $[28,76,77]$, and to explore the impact of increased complexity of physics schemes and coupling to other ocean and land models [78].

\section{Intercomparison Projects and International Collaboration}

Even before GCRMs became computationally feasible for groups outside of Japan, CMMAP, using its SuperParameterized Global Models, began a program of intercomparison with the NICAM group. Along with this, the Dynamical Core Model Intercomparison Project (DCMIP; held also as DYCORE-2008) initiated a series of workshops in 2008, 2012, and 2016 [79], defining test cases that became important for the development and testing of GCRMs. The Icosahedralgrid Models for Exascale Earth System Simulations (ICOMEX) provided an additional framework for comparison of 
icosahedral dynamical core models (ICON, NICAM, DYNAMICO, and MPAS), most of which have since been developed into full-fledged GCRMs.

NICAM also joined the Aqua Planet Experiment Project $[80,81]$, where it was compared to traditional, low-resolution hydrostatic climate and global weather models, and two Coupled Model Intercomparison Project Phase 6 (CMIP6) projects: the Cloud Feedback Model Intercomparison Project (CFMIP, CFMIP2 [82]) and HighResMIP [83] where its simulations are compared to those by conventional climate models. For CFMIP, NICAM contributed aqua planet simulations, and realistic configurations are used for HighResMIP. More recently, NICAM has been used, along with ICON, to compare to CRMs in the framework for the RCEMIP [24].

NICAM has also been evaluated in more realistic/ operational settings for studies of the MJO [84], tropical cyclones (TYMIP-G7 [85]), and contributed to the Athena Project [86] in which it was compared to higher resolution hydrostatic integrations with IFS [87]. For operational models, the High Impact Weather Prediction Project (HIWPP; https:// hiwpp.noaa.gov/) was coordinated by the National Oceanographic and Atmospheric Administration (NOAA) in the USA, to prepare GCRMs for use operationally.

Today, with GCRMs having been developed by a number of groups outside of Japan, it has become possible, for the first time, to compare GCRMs with each other, so as to identify their generic versus particular features. This intercomparison, called DYnamics of the Atmospheric general circulation Modeled On Nonhydrostatic Domains (DYAMOND, https://www.esiwace. $\mathrm{eu} /$ services/dyamond), compares 40-day simulations of eight nonhydrostatic models ICON, NICAM, SAM, FV3, GEOS-5, MPAS, ARPEGE-NH, and the Unified Model (UM) [30]. Within DYAMOND, the GCRMs are also being compared to the hydrostatic version of IFS-ST, and all output is being made available for open use by the community through the Center for Excellence in Simulation of Weather and Climate in Europe, a Horizon 2020 project funded by the European Union (https:// www.cmcc.it/projects/esiwace-centre-of-excellence-insimulation-of-weather-and-climate-in-europe).

The first results (precipitation from a subset of these models) from DYAMOND are presented in Fig. 1. This shows global distributions of 1-month averaged precipitation for the integration period of the DYAMOND simulation (August 10 to September 10, 2016). The Intertropical Convergence Zone (ITCZ) is located at almost the same latitudinal zone and the zonal mean precipitation is very comparable to that of the satellite-based observation as indicated by Fig. 5 of [30], which compares the zonal average of precipitation between the GCRMs and the observation. Figure 1 also indicates globally averaged values of the precipitation, which are within the range between 3.05 and $3.25 \mathrm{~mm} \mathrm{day}^{-1}$. An overall similarity across models in terms of geographical distribution and quantities is impressive, especially when it is realized that some of the models are being run for the first time as GCRMs, that no specific tuning of precipitation has been applied and that the energy balance does not severely constrain precipitation. The first result shown by Fig. 1 provides one aspect of the advantages of GCRMs, which is described in more detail in the next section.

\section{Advantages of GCRMs}

GCRMs better represent physical understanding than do traditional climate and global numerical weather prediction models because they solve the correct equations over a larger range of scales. Only practical (computational) issues inhibit their more widespread use. This and other, less appreciated, advantages of GCRMs are summarized below, as follows (Table 1, [88]), in the form of a top ten list, including substantiating references for each point. Most references are taken from the literature describing NICAM, as until recently it was the only GCRM in active use.

1. Representation of the global mesoscale: An irony of modern climate science is that circulation systems that most impact humans and the environment are largely ignored - neither are they parameterized nor are they explicitly represented - by climate models. These circulations define the atmospheric mesoscale [89], and phenomena and GCRMs are designed to resolve exactly these scales which include as exemplified by the long literature on the application of CRMs to studies of organized convective systems, wind-storms, and squalls. GCRMs have likewise been applied to studies of diurnal circulations [69, $86,90,91]$ and are beginning to be used to study local topographic effects on precipitating systems (e.g., [92]). GCRMs are designed to resolve exactly this range of scales, the scale of storms, and their impacts. The better coupling with cloud, radiation, and land-surface processes are introduced in the global mesoscale.

2. Multiscale scale interactions of convection: GCRMs naturally simulate the multiscale structure of convective systems that is particularly important for their evolution in the tropics, from individual deep convection, cloud clusters, and large-scale organized convective systems, as already demonstrated by [64], including a realistic representation of the MJO as a famous example [65, $70,74]$. The inner structures of tropical cyclones, such as the eye-wall and associated convective extremes, are simulated together with the large-scale and synoptic scale environmental fields which affect evolution of tropical cyclones [73, 93, 94].

3. Circulation-driven microphysical processes: Unlike models with parameterized convection and clouds, GCRMs explicitly link the cloud-scale circulations to cloud microphysical processes. This is giving new 
Fig. 1 Global distribution of the average precipitation simulated by six GCRMs for the DYAMOND project between August 10 and September 10, 2016. From top to bottom with left to right: NICAM $3.5 \mathrm{~km}$, ICON $2.5 \mathrm{~km}$, SAM $4.3 \mathrm{~km}, \mathrm{FV} 3$ $3.3 \mathrm{~km}$, IFS $4 \mathrm{~km}$, and MPAS $3.8 \mathrm{~km}$. Numbers just above each figure are averaged precipitation over the sphere
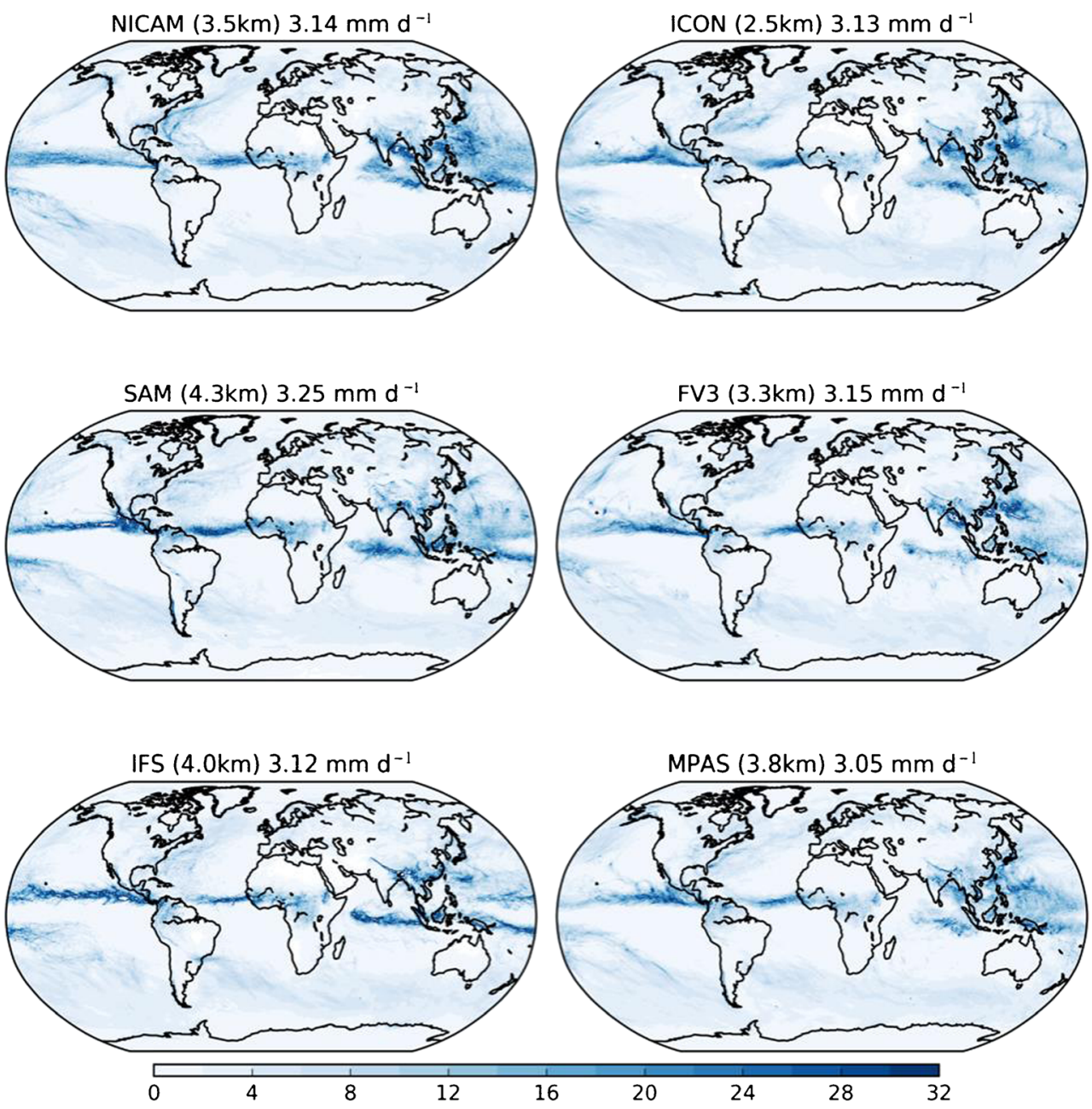

impetus to questions about the role of cloud microphysical processes and the amount of complexity they must entail to represent the climate (cf. $[95,96])$ and the nature of its extremes.

4. Turbulence and gravity waves: Kilometer-scale disturbances - for instance from topographic effects and ensuing wave excitation-are captured globally and their characteristics and effects on larger-scale circulations can be analyzed as exemplified by studies with GEOS-5 [59, 60]. GCRMs also allow the tropopause dynamics with mesoscale disturbances to be simulated [97-101]. Energy spectra of GCRMs also convincingly reproduce the observed transition from the synoptic to the mesoscale regimes [102, 103].

5. Synergy with satellite observations: Conventional climate models struggle to make critical use of observations. In contrast, because cloud properties are comparable in scale to those provided by satellite observations (e.g., Himawari-8 [104]) and more comparable in scale to surface observations, and the link to circulations are direct, GCRMs make it easier to critically evaluate global simulations of the distribution of clouds, rain, and winds in GCRMs. Examples of such efforts are myriad: particularly, the use of instrument simulators to interpret satellite measurements is an area of increasing inquiry (e.g., $[28,76,77,95,105-107])$ but also to point measurements as in [108].

6. Nature runs as a source of empiricism: With their kilometer-scale global mesh, GCRM simulations can be used as a source of empiricism, which is why we call them nature runs. A nature run is a free-running numerical model simulation with minimal knowledge of any realistic atmospheric state but with a realistic climatology consisting of realistic weather patterns [109]. In this fashion, they function as natural laboratories for developing and testing algorithms in three-dimensional and time continuous space - something that is not possible with observations [110]. The GEOS 7-km Nature Run is widely used for the OSSE community $[55,58]$, for this purpose. Using a NICAM simulation in a similar vein, Miyakawa et al. [111] discovered the threefold structure of convective momentum transport associated with the MJO, something that would have been difficult to be captured by observation. 
Table 1 Top ten reasons why GCRM is a great leap

1. Represents the mesoscale ( 2 to $2000 \mathrm{~km}$ ) and its link to the general circulation

2. Represents the multiscale physics and scale interactions inherent in atmospheric moist convection

3. Represents the dynamic and thermodynamic drivers of cloud microphysical processes

4. Represents the mean state to which small scale turbulence responds and captures gravity, and inertial-gravity waves, and thereby main mechanisms of wave mean flow interaction

5. Simulates the same quantities that the satellites observe, enabling the critical application of these observations

6. Provides an additional source of empiricism using "nature runs" with hector or kilometer-scale simulations on short time periods

7. Opens the possibility of global cloud-resolving earth system models by enabling important coupling pathways to the ocean

8. Allows for one model and avoids the need for (and challenges of) downscaling thereby providing a direct link to application and impact communities

9. Represents main constituent transport mechanisms, thus linking observed concentrations of important trace species to their sources and sinks

10. Advances information science, by spurring developments in both hardware and software, e.g., to deal with data flows, or hierarchical computational architecture

This list is modified from that presented by [88] at the 2018 General Assembly of the European Geosciences

7. Toward global cloud-resolving earth system models: Now GCRMs are beginning to be coupled with ocean and land models with similar (kilometer scale) resolution. They provide a consistent basis for linking the hydrological cycle to the carbon cycle. The first atmosphere-ocean coupled GCRMs are in development. In the case of NICAM, the coupled model NICOCO, albeit at coarser resolution, has been used to investigate an MJO effect on ENSO [78]. Next-generation models will fully resolve both the atmosphere and ocean mesoscale and improve the physical foundation for climate prediction.

8. Consistent downscaling for impact studies: Historically, two, or more, models with high-resolution regional and coarse resolution global models have been used for impact studies. This approach requires a lot of efforts of maintenance or development of multi-models and introduces spurious forcings arising from different physical parameterizations for each model. GCRMs are being used as a single model to seamlessly couple, either through regional stretching [112-115] or nesting [29, $116]$ kilometer to hectometer scale circulations of interest to impact communities.

9. Tracer transport: High-resolution flow fields including simulated upward convective mass flux together with detailed topography channeling greatly affect transport processes and cannot be captured by GCMs; thus, GCRMs provide a more natural link between emissions and resultant concentrations of a variety of substances, from $\mathrm{CO}_{2}$ - which will be important for tracking emission inventories [61] — to particulate matter, which is important for air quality and quantifying aerosol cloud interactions [117].

10. Advancing computational infrastructure: For new computer projects, GCRMs provide applications with the highest resolution and producing huge amounts of output. They thus require massive computational nodes and disks and spur innovative computational technologies, both in hardware and software. In fact, many of the computational tools we will use in the future may well have their origins in efforts to effectively run and analyze GCRMs, examples include the "K computer" [118, 119] and post-K computer in Japan. Likewise in Europe, GCRMs are providing the underpinnings for new technology projects under the framework of the Extreme Earth initiative (http://www.extremeearth.eu/).

\section{What Is in a Model?}

We define GCRMs to be models that can represent nonhydrostatic vertical accelerations associated with deep precipitating convection globally. By directly simulating the motions associated with the bulk of the vertical heat transport in convective storms, GCRMs forgo the need for convective parameterization. As GCRMs come into more commonplace use, for instance nine models contributed output to the DYAMOND intercomparison [30], differences in approaches are becoming apparent. Here and in Appendix 1, we briefly describe seven of the DYAMOND models with the aim of highlighting differences and similarities among GCRMs.

The main quality that GCRMs share is the space and timescales which they explicitly simulate. The equations they solve, the methods they use to solve them, and their approach to representing unresolved processes all differ, sometimes substantially. Table 2 summarizes some important distinctions which are elaborated upon below. The fluid-dynamical representation (the dynamical core) can be categorized both by approximations applied in deriving a set of governing (continuous) equations to be solved and approximations made in constructing the discrete analogs from which numerical solutions are eventually constructed. The representation of unresolved processes (radiation, cloud processes, turbulence, land-surface processes) introduces yet further distinctions. Most GCRMs solve the fully compressible equations using discrete analogs constructed in physical space and include parameterizations for cloud processes, turbulence, radiative 
Table 2 Configuration of GCRMs used in DYAMOND

\begin{tabular}{|c|c|c|c|c|c|c|}
\hline & Grid & Time integration scheme & $\mathrm{dx}[\mathrm{km}]$ & Lev & Top $[\mathrm{km}]$ & References \\
\hline NICAM & ICO, A-grid [2] & Fully compressible, split-explicit, vertically implicit & 3.5 & 78 & 50 & {$[3,4]$} \\
\hline ICON & ICO [5] & Fully compressible, split-explicit, vertically implicit & 2.5 & 90 & 75 & {$[6]$} \\
\hline MPAS & Voronoi, C-grid [7] & Fully compressible, split-explicit, vertically implicit & 3.8 & 75 & 40 & {$[7,8]$} \\
\hline FV3 & $\begin{array}{l}\text { Cube, C-D staggering for } \\
\text { optimal PV advection [9] }\end{array}$ & $\begin{array}{l}\text { Fully compressible, forward-in-time finite-volume scheme, } \\
\text { vertically Lagrangian }\end{array}$ & 3.3 & 79 & 39 & {$[10,11]$} \\
\hline GEOS-5 & Same as FV3 & Same as FV3 & 3.3 & 132 & 80 & {$[9,12]$} \\
\hline SAM & Lat-Lon, C-grid [13] & Anelastic & 4.3 & 74 & 37 & {$[41]$} \\
\hline IFS-ST & Octo, spectral [14] & Semi-implicit semi-Lagrangian & 4.8 & 137 & 80 & {$[14,15]$} \\
\hline
\end{tabular}

ICO icosahedral grid, Voronoi Voronoi tessellation, Cube cubed sphere, Lat-Lon latitude-longitude grids, Octo cubic octahedral reduced grid, $d x$ the horizontal grid size is defined by a square of the largest area of a grid cell, Lev number of vertical levels, Top model top

energy transfer, and surface processes, but substantial differences exist among models as outlined below.

Most models solve the fully compressible equations and hence account for sound waves. This can be done in different ways, but most models take the horizontally explicit and vertically implicit method with the split-explicit technique adopted following [11]. SAM is an exception as it is an anelastic model. The anelastic equations $[12,13]$ solve for perturbations around a uniform basic state and are thus best justified for atmospheres with small departures about this mean state. They are thus historically used for limited-area simulations. There is an extensive literature on the foundations (and errors) associated with assumptions made in the anelastic models [120-122] but only now has it become possible to assess these errors in comparison to other uncertainties in the model formulation on global scales. If similarities in Fig. 1 are any guide, the effects of these errors are likely to be subtle. The IFS-ST also differs from the other models through its use of the quasi-static (primitive) equations [123], but even in this case, where nonhydrostatic vertical accelerations are neglected, errors are either compensated by other approximations or are likewise subtle. Because some of the approximate representations of the continuous equations can be computationally advantageous, a better understanding of errors that are caused by these approximations in full-scale global simulations is desirable.

Considerable differences are evident (Table 2) in how the grids are constructed, how variables are distributed on these grids, and how numerical discrete approximations to differential operators are constructed. Icosahedral grids (NICAM, ICON, MPAS), cubic grids (FV3, GEOS-5), and octahedral grids are popular because they provide a quasi-uniform mesh [45]. This minimizes the number of grid points required to achieve a given resolution and also leads to a quasi-uniform balance between the chosen time-step and advective timescale. Of the models we review, only SAM uses a regular latitude-longitude grid, and the IFS uses a spectral-transform method. Most models use a staggered (C-grid) grid in physical space, and NICAM and IFS-FVM use a collocated (A-grid) grid. FV3 is based on C-D staggering for optimal potential vorticity (PV) advection. Even for the same horizontal grid, models would still differ in their representation of the vertical coordinate and the distribution of vertical degrees of freedom. This particularly impacts their ability to represent orographic influences on the flow, and even for the same horizontal discretization, it can lead to substantial differences in the representation of orographic features (see, e.g., [30]). The considerable differences in how the continuous equations are approximated make it challenging to separate the influence of the particular implementation of a given set of equations, from inherent differences in the equations themselves.

Each of the seven GCRMs reviewed here chooses its own combination of methods to represent unresolved processes. Differences among schemes are, particularly as related to the representation of cloud processes, more similar to differences in cloud-resolving (or LES) models than among climate and weather forecast models. Notable are differences in the representation of convective transports. Here, an important question that arises is when the distortions introduced by parameterizations are less deleterious than those introduced by a poor resolution of the requisite scales of motion. Similar questions could be posed in terms of the representation of orographic gravity-wave drag. Although the microphysical approaches adopted by the GCRMs reviewed here are quite similar, this likely reflects consensus as to the importance of computational expediency, as a major open question is to what extent must microphysical degrees of freedom be simulated to adequately simulate larger-scale circulation features. A similar question arises in the representation of mixing by unresolved turbulent motions, but in contrast to conventional climate models, the more direct link between these small scale processes and the resolved state encourages renewed attempts to understand in what way uncertainties on small scales influence the largescale structure of the climate system. 


\section{Conclusions}

GCRMs are becoming a common tool for atmospheric studies. The transition from GCMs to GCRMs is a step change of global modeling mainly because the cumulus parameterization scheme is no longer prerequisite but also because orographic drag is much better resolved. With GCRMs, global atmospheric circulations can be understood in terms of mesoscale systems and a variety of disturbances including gravity waves and turbulences are embedded in GCRM simulations. Clouds represented by GCRMs are more directly comparable to satellite observations and they can be evaluated and improved in terms of cloud microphysics. GCRMs are currently being used for ever wider areas of research, and they will be also more adapted for operational weather forecasts and climate projection studies [124].

Although GCRMs possess many good points, almost as much can be learned for the improvements they bring as the ones they do not. For example, in what (by GCRMs standards) is rather coarse resolution, a long-term simulation by [71] showed that global precipitation distributions have a double ITCZ structure, which is known a common bias in many GCMs [125-127]. Work is ongoing to establish to what extent this represents structural deficiencies in the model, or the influence of parameterizations that do not go away as the grid is refined. Global cloud distributions are less ambiguously sensitive to cloud microphysics schemes and suitable choice of parameters or processes in the schemes is generally required to obtain realistic cloud amount or thickness $[63,128]$. It is also appreciated that even at a $1-\mathrm{km}$ grid scale, the magnitude of the vertical motions within convective cores has not yet convergedsomething the representation of microphysical processes may need to account for [31]. The sub-grid processes such as shallow convection, lateral mixing including entrainment/detrainment of convective clouds, and boundary layer processes are also issues requiring further consideration in GCRMs. GCRMs do not solve all the problems, but they solve some problems and create a more physical basis for framing and resolving the issues that remain.

Further higher resolution GCRMs, that is global LES models with mesh size of $\mathrm{O}(100 \mathrm{~m})$, will be a next target of high-resolution modeling to resolve the abovementioned sub-grid processes. Toward this end, ICON has been tested for a wide area LES for the whole Germany [116]. We expect for a first global LES simulation to emerge in the near future, but the use of global LES models for research and operations will take considerably longer [46]. Although further increase of the spatial resolution of global models will be continuously demanded, GCRMs will be a major player for the new type of global atmospheric models for the coming decade.
Acknowledgments The DYAMOND project is supported by ESiWACE which is coordinated by the German Climate Computing Center (DKRZ) and funded by the European Union's Horizon 2020 program under grant no. 675191. DKRZ also is responsible for the DYAMOND data archiving as described in the DYAMOND overview paper [30]. Figure 1 is a preliminary look at DYAMOND output based on analysis by Daniel Klocke. The NICAM simulation of DYAMOND was conducted by Ryosuke Shibuya, and the ICON runs were performed by Luis Kornblueh with support from the project High-Definition Clouds and precipitation for Climate Prediction - $\mathrm{HD}(\mathrm{CP})^{2}$ - funded by the German Ministry of Education and Research (BMBF). The authors thank Wojciech Grabowski and an anonymous reviewer for the critical comments on the first manuscript. Their comments constructively guided revisions which substantially improved the manuscript. The authors also thank Christian Jakob and Steve Krueger for input reconstruing the early history of Cloud-Resolving and Cumulus Ensemble Modeling. The NICAM simulation is conducted under Future LAtency core-based General-purpose Supercomputer with HIgh Productivity (FLAGSHIP2020 project), which are promoted by the Ministry of Education, Culture, Sports, Science and Technology (MEXT), Japan, and contributed by Integrated Research Program for Advancing Climate Model (TOUGOU) by MEXT. Marat Khairoutdinov was supported by the NSF Grant AGS1418309 to Stony Brook University and also by the NCAR-Wyoming Supercomputer Center, where SAM simulation was performed. On behalf of all authors, the corresponding author states that there is no conflict of interest.

\section{Appendix 1}

\section{Description of GCRMs}

\section{NICAM}

The NICAM (http://nicam.jp/) has a dynamical core of the icosahedral mesh structure with the conservative nonhydrostatic equation system $[1,34,35]$. Development of NICAM began around 2000 and the first global cloudresolving simulation with the mesh size about $3.5 \mathrm{~km}$ was conducted by [64] for the aqua planet configuration. Then, the MJO simulation with the same resolution was conducted by [65] with the realistic land and ocean distribution. The overall description of NICAM is given by $[34,35]$. The recent outcomes of NICAM are described by $[35,62,63]$.

\section{ICON}

Similar to NICAM, ICON adopts a triangular tiling of the sphere, progressively refined from an icosahedral $[36,37,50]$. ICON development, which also began in 2000 , emphasized the provision of a flexible modeling environment, as it allows multi-level two-way nesting over both global and limited-area domains. It has physics packages that allow it to perform idealized (e.g., [129]) and realistic domain simulations [116] as an LES model using the Smagorinsky sub-grid-scale closure [51], to run at stormresolving scales [29], as an operational weather forecast model [36] and as a component of a coupled climate model [130]. The first storm-resolving ( $2.5 \mathrm{~km}$ horizontal mesh) global simulations were performed in support of the DYAMOND project. 


\section{MPAS}

MPAS (https://mpas-dev.github.io) is a collaborative project for developing atmosphere, ocean, and other Earth system simulation components for use in climate, regional climate, and weather studies. At the heart of the atmospheric component, MPAS-A [38] lies a global nonhydrostatic atmosphere solver developed at the National Center for Atmospheric Research (NCAR). Like the other MPAS components, MPAS-A uses finitevolume numerics discretized on centroidal Voronoi meshes. MPAS-A is intended to expand the ability of the weather and climate community to conduct fine-scale modeling of moist convection. To facilitate this goal, MPAS-A supports quasi-uniform resolution meshes, which are similar to icosahedral (hexagonal) meshes, and variable horizontal resolution meshes with local mesh refinement. Quasi-uniform meshes with $\mathrm{O}(1 \mathrm{~km})$ resolution are able to resolve motions on scales from severe thunderstorms to global modes of variability and therefore ideal for GCRM applications.

\section{FV3}

GFDL's GCRM is FV3 [54, 131]. The FV3 dynamical core uses the forward-in-time finite-volume scheme [132], pressure gradient force of [133], and vertically Lagrangian discretization of [39]. Vertically propagating sound waves are treated semi-implicitly. Advection of scalars (ozone and water species) uses the positive-definite two-dimensional advection scheme of [134] based on the piecewiseparabolic method. In the dynamics, grid-scale noise is dissipated through the use of an eighth-order divergence damping, Smagorinsky (second order) damping, and a weak sixth-order damping on the vorticity and potential temperature.

GFDL's participation to the DYAMOND project is performed with the so-called finite-volume Global Forecast System (fvGFS). For physics, GFDL six-category cloud microphysics [135] is used. The rest of the modeling system is from NCEP's Global Forecast System (GFS), including the planetary boundary layer scheme, the shallow convection scheme, and the Noah land model. In all experiments, the deep convective scheme and all forms of gravity-wave drag are disabled, but a scale-aware mountain blocking parameterization (due to the unresolved sub-grid orography) is applied.

\section{GEOS-5}

The GEOS model is a comprehensive earth system model developed for diverse applications in climate and weather. These applications include data assimilation, numerical weather predication, subseasonal to seasonal prediction, and full tropospheric and stratospheric chemistry modeling. The diverse configurations of GEOS are assembled from a unified library of modular components using the Earth System Modeling Framework (ESMF).

GEOS-5 is based on the same dynamical core FV3. GEOS is designed to be a scale-aware modeling system with a seamless capability to support global climate simulations at horizontal resolutions of $50-100 \mathrm{~km}$ down to global cloudresolving resolutions approaching $1 \mathrm{~km}$ [40]. A scalable suite of physics components is built around FV3 dynamical core [54].

\section{SAM}

The SAM is formulated on the latitude-longitude grid using the code recently refactored from the original limited-area code on the Cartesian grid [41]. Unlike most other GCRMs, SAM solves the nonhydrostatic momentum equations in the anelastic approximation, which eliminates sound waves. Also in contrast to many other GCRMs, SAM represents terrain using a box-fill method, when the grid cells below the topography are forced to have zero velocity. The version used for the DYAMOND uses solid walls poleward of $89^{\circ}$, to avoid the "pole problem." The development version of SAM resolves motions at the pole.

\section{IFS-ST and IFS-FVM}

The IFS-ST is used for operational weather prediction at ECMWF, currently with a global resolution of $9 \mathrm{~km}$ for 10-day deterministic forecasts and $18 \mathrm{~km}$ for a 50 member 15-day ensemble prediction. The IFS-ST is a spectral-transform model that uses spherical harmonics to represent physical fields on the sphere. The spectral representation is combined with a cubic octahedral Gaussian grid to calculate nonlinear terms and physical parameterizations in grid-point space. The model is optimized to be as computationally efficient as possible, for instance through the use of a semi-implicit semiLagrangian time stepping scheme that permits very large timesteps [42, 136], and efforts to match the information content in the simulation with the numerical precision of its representation [137, 138].

IFS-FVM is developed with approaches more similar to the other GCRMs in that it solves the compressible equations in physical space $[43,139,140]$, on an A-Grid similar to NICAM. The equations are solved using semi-implicit time stepping. The IFS-FVM shares the physical parameterizations with IFS-ST [44]. 
Open Access This article is distributed under the terms of the Creative Commons Attribution 4.0 International License (http:// creativecommons.org/licenses/by/4.0/), which permits unrestricted use, distribution, and reproduction in any medium, provided you give appropriate credit to the original author(s) and the source, provide a link to the Creative Commons license, and indicate if changes were made.

\section{References}

1. Tomita H, Satoh M. A new dynamical framework of nonhydrostatic global model using the icosahedral grid. Fluid Dyn Res. 2004;34:357-400.

2. Stevens B, Bony S. What are climate models missing? Science. 2013;340:1053-4.

3. Dudhia J, Moncrieff MW. A three-dimensional numerical study of an Oklahoma squall line containing right-flank supercells. J Atmos Sci. 1988;46:3363-91.

4. GEWEX Cloud System Science Team. The GEWEX Cloud System Study (GCSS). Bull Am Meteorol Soc. 1993;74:387-400.

5. Moncrieff MW, Krueger SK, Gregory D, Redelsperger J-L, Tao W-K. GEWEX Cloud System Study (GCSS) Working Group 4: Precipitating convective cloud systems. Bull Am Meteorol Soc. 1997;78:831-46.

6. Randall D, Khairoutdinov M, Arakawa A, Grabowski W. Breaking the cloud parameterization deadlock. Bull Am Meteorol Soc. 2003;84:1547-64.

7. Soong S-T, Ogura Y. Response of tradewind cumuli to large-scale processes. J Atmos Sci. 1980;37:2035-50.

8. Krueger SK. Numerical simulation of tropical cumulus clouds and their interaction with the subcloud layer. J Atmos Sci. 1988;45: 2221-50.

9. Ogura Y. The evolution of a moist convective element in a shallow, conditionally unstable atmosphere: a numerical calculation. J Atmos Sci. 1963;20:407-24.

10. Miller MJ, Pearce RP. A three-dimensional primitive equation model of cumulonimbus convection. Q J R Meteorol Soc. 1974;100:133-54.

11. Klemp JB, Wilhelmson RB. The simulation of three-dimensional convective storm dynamics. J Atmos Sci. 1978;35:1070-96.

12. Schlesinger RE. A three-dimensional numerical model of an isolated deep convective cloud: preliminary results. J Atmos Sci. 1975;32:934-57.

13. Clark TL. Numerical simulations with a three-dimensional cloud model: lateral boundary condition experiments and multicellular severe storm simulations. J Atmos Sci. 1979;36:2191-215.

14. Lipps FB, Hemler RS. A scale analysis of deep moist convection and some related numerical calculations. J Atmos Sci. 1982;39: 2192-210.

15. Weisman ML, Skamarock WC, Klemp JB. The resolution dependence of explicitly modeled convective systems. Mon Weather Rev. 1997;125:527-48.

16. Langhans W, Schmidli J, Schär C. Bulk convergence of cloudresolving simulations of moist convection over complex terrain. $\mathrm{J}$ Atmos Sci. 2012;69:2207-28.

17. Prein AF, Langhans W, Fosser G, Ferrone A, Ban N, Goergen K, et al. A review on regional convection-permitting climate modeling: demonstrations, prospects, and challenges. Rev Geophys. 2015;53:323-61.

18. Tripoli GJ, Cotton WR. Numerical study of an observed orogenic mesoscale convective system. Part 1: simulated genesis and comparison with observations. Mon Weather Rev. 1989;117:273-304.
19. Grabowski WW, Wu X, Moncrieff MW. Cloud-resolving modeling of tropical cloud systems during Phase III of GATE. Part I: two-dimensional experiments. J Atmos Sci. 1996;53:3684-709.

20. Xu K-M, Randall DA. Explicit simulation of cumulus ensembles with the GATE Phase III data: comparison with observations. J Atmos Sci. 1996;53:3710-36.

21. Bernardet LR, Cotton WR. Multiscale evolution of a derechoproducing mesoscale convective system. Mon Weather Rev. 1998;126:2991-3015.

22. Nakajima K, Matsuno T. Numerical experiments concerning the origin of cloud clusters in the tropical atmosphere. J Meteorol Soc Japan. 1988;66:309-29.

23. Tompkins BAM, Craig GC. Radiative-convective equilibrium in a three-dimensional cloud-ensemble model. Q J R Meteorol Soc. 1998;124:2073-97.

24. Wing AA, Reed KA, Satoh M, Stevens B, Bony S, Ohno T. Radiative-convective equilibrium model intercomparison project. Geosci Model Dev. 2018;11:793-813.

25. Mellado JP. Cloud-top entrainment in stratocumulus clouds. Annu Rev Fluid Mech. 2017;49:145-69.

26. Mellado JP, Bretherton CS, Stevens B, Wyant MC. DNS and LES for simulating stratocumulus: better together. J Adv Model Earth Syst. 2018;10:1421-38.

27. Stevens B, Moeng C-H, Ackerman AS, Bretherton CS, Chlond A, de Roode S, et al. Evaluation of large-eddy simulations via observations of nocturnal marine stratocumulus. Mon Weather Rev. 2005; 133:1443-62.

28. Matsui T, Chern J-D, Tao W-K, Lang S, Satoh M, Hashino T, et al. On the land-ocean contrast of tropical convection and microphysics statistics derived from TRMM satellite signals and global storm-resolving models. J Hydrometeorol. 2016;17:1425-45.

29. Klocke D, Brueck M, Hohenegger C, Stevens B. Rediscovery of the doldrums in storm-resolving simulations over the tropical Atlantic. Nat Geosci. 2017;10:891-6.

30. Stevens B, Satoh M, Auger L, et al. (2019) DYAMOND: the DYnamics of the Atmospheric general circulation Modeled On Non-hydrostatic Domains. Prog Earth Planet Sci. (in review).

31. Miyamoto Y, Kajikawa Y, Yoshida R, Yamaura T, Yashiro H, Tomita H. Deep moist atmospheric convection in a subkilometer global simulation. Geophys Res Lett. 2013;40:4922-6.

32. Sadourny R, Arakawa A, Mintz Y. Integration of the nondivergent barotropic vorticity equation with an icosahedral-hexagonal grid for the sphere. Mon Weather Rev. 1968;96:351-6.

33. Williamson DL. Integration of the barotropic vorticity equation on a spherical geodesic grid. Tellus. 1968;20:642-53.

34. Satoh M, Matsuno T, Tomita H, Miura H, Nasuno T, Iga S. Nonhydrostatic icosahedral atmospheric model (NICAM) for global cloud resolving simulations. J Comput Phys. 2008;227: 3486-514.

35. Satoh M, Tomita H, Yashiro H, Miura H, Kodama C, Seiki T, et al. The non-hydrostatic icosahedral atmospheric model: description and development. Prog Earth Planet Sci. 2014;1:18.

36. Zängl G, Reinert D, Rípodas P, Baldauf M. The ICON (ICOsahedral Non-hydrostatic) modelling framework of DWD and MPI-M: description of the non-hydrostatic dynamical core. Q J R Meteorol Soc. 2015;141:563-79.

37. Giorgetta MA, Brokopf R, Crueger T, Esch M, Fiedler S, Helmert $\mathrm{J}$, et al. ICON-A, the atmosphere component of the ICON Earth system model: I. model description. J Adv Model Earth Syst. 2018;10:1613-37.

38. Skamarock WC, Klemp JB, Duda MG, Fowler LD, Park S-H, Ringler TD. A multiscale nonhydrostatic atmospheric model using centroidal Voronoi tesselations and C-grid staggering. Mon Weather Rev. 2012;140:3090-105.

39. Lin S-J. A "vertically Lagrangian" finite-volume dynamical core for global models. Mon Weather Rev. 2004;132:2293-307. 
40. Putman WM, Suarez M. Cloud-system resolving simulations with the NASA Goddard Earth Observing System global atmospheric model (GEOS-5). Geophys Res Lett. 2011;38:L16809.

41. Khairoutdinov MF, Randall DA. Cloud resolving modeling of the ARM summer 1997 IOP: model formulation, results, uncertainties, and sensitivities. J Atmos Sci. 2003;60:607-25.

42. Wedi N, Bauer P, Deconinck W, Diamantakis M, Hamrud M, Kuehnlein $\mathrm{C}$, et al. The modelling infrastructure of the Integrated Forecasting System: recent advances and future challenges. ECMWF Tech Memo. 2015;760:48.

43. Smolarkiewicz PK, Deconinck W, Hamrud M, Kühnlein C, Mozdzynski G, Szmelter J, et al. A finite-volume module for simulating global all-scale atmospheric flows. J Comput Phys. 2016;314:287-304.

44. Kühnlein C, Deconinck W, Klein R, Malardel S, Piotrowski ZP, Smolarkiewicz PK, et al. FVM 1.0: a nonhydrostatic finitevolume dynamical core for the IFS. Geosci Model Dev. 2019;12:651-76.

45. Williamson DL. The evolution of dynamical cores for global atmospheric models. J Meteorol Soc Japan. 2007;85B:241-69.

46. Grabowski WW. Towards global large eddy simulation: superparameterization revisited. J Meteorol Soc Japan. 2016;94:327-44.

47. Matsuno T. Prologue: tropical meteorology 1960-2010 - personal recollections. Meteorol Monogr. 2016;56:7-15.

48. Satoh M, Tomita H, Miura H, Iga S, Nasuno T. Development of a global cloud resolving model - a multi-scale structure of tropical convections. J Earth Simul. 2005;3:11-9.

49. Satoh M, Tomita H. Development of a global cloud-resolving atmospheric model with a quasi-uniform grid and numerical simulation of tropical cloud clusters (in Japanese). Tenki. 2008;55: 451-6.

50. Wan H, Giorgetta MA, Zängl G, Restelli M, Majewski D, Bonaventura L, et al. The ICON-1.2 hydrostatic atmospheric dynamical core on triangular grids - part 1: formulation and performance of the baseline version. Geosci Model Dev. 2013;6:735-63.

51. Dipankar A, Stevens B, Heinze R, Moseley C, Zängl G, Giorgetta $\mathrm{M}$, et al. Large eddy simulation using the general circulation model ICON. J Adv Model Earth Syst. 2015;7:963-86.

52. Khairoutdinov M, Randall D, DeMott C. Simulations of the atmospheric general circulation using a cloud-resolving model as a superparameterization of physical processes. J Atmos Sci. 2005;62:2136-54.

53. Randall DA. Beyond deadlock. Geophys Res Lett. 2013;40:5970-6.

54. Putman WM, Lin S-J. Finite-volume transport on various cubedsphere grids. J Comput Phys. 2007;227:55-78.

55. Gelaro R, Putman WM, Pawson S, et al. Evaluation of the 7-km GEOS-5 nature run. NASA Tech Rep Ser Glob Model Data Assim. 2015;36:1-305.

56. Privé NC, Errico RM. Temporal and spatial interpolation errors of high-resolution modeled atmospheric fields. J Atmos Ocean Technol. 2015;33:303-11.

57. Errico RM, Privé NC, Carvalho D, et al. Description of the GMAO OSSE for weather analysis software package: version 3 . NASA Tech Rep Ser Glob Model Data Assim. 2017;48:1-144.

58. Reale O, Achuthavarier D, Fuentes M, Putman WM, Partyka G. Tropical cyclones in the 7-km NASA global nature run for use in observing system simulation experiments. J Atmos Ocean Technol. 2017;34:73-100.

59. Holt LA, Alexander MJ, Coy L, Molod A, Putman W, Pawson S. Tropical waves and the quasi-biennial oscillation in a 7-km global climate simulation. J Atmos Sci. 2016;73:3771-83.

60. Holt LA, Alexander MJ, Coy L, Liu C, Molod A, Putman W, et al. An evaluation of gravity waves and gravity wave sources in the Southern Hemisphere in a $7 \mathrm{~km}$ global climate simulation. Q J R Meteorol Soc. 2017;143:2481-95.
61. Putman WM, Ott L, Darmenov A, daSilva A. A global perspective of atmospheric carbon dioxide concentrations. Parallel Comput. 2016;55:2-8.

62. Satoh M, Tomita H, Yashiro H, Kajikawa Y, Miyamoto Y, Yamaura T, et al. Outcomes and challenges of global highresolution non-hydrostatic atmospheric simulations using the $\mathrm{K}$ computer. Prog Earth Planet Sci. 2017;4:13.

63. Satoh M, Noda AT, Seiki T, Chen Y-W, Kodama C, Yamada Y, et al. Toward reduction of the uncertainties in climate sensitivity due to cloud processes using a global non-hydrostatic atmospheric model. Prog Earth Planet Sci. 2018;5:67.

64. Tomita H, Miura H, Iga S, Nasuno T, Satoh M. A global cloudresolving simulation: preliminary results from an aqua planet experiment. Geophys Res Lett. 2005;32:L08805.

65. Miura H, Satoh M, Nasuno T, Noda AT, Oouchi K. A MaddenJulian oscillation event realistically simulated by a global cloudresolving model. Science. 2007;318:1763-5.

66. Miyamoto Y, Yoshida R, Yamaura T, Yashiro H, Tomita H, Kajikawa Y. Does convection vary in different cloud disturbances? Atmos Sci Lett. 2015;16:305-9.

67. Miyamoto Y, Yamaura T, Yoshida R, Yashiro H, Tomita H, Kajikawa Y. Precursors of deep moist convection in a subkilometer global simulation. J Geophys Res. 2016;121: 12080-8.

68. Kajikawa Y, Miyamoto Y, Yoshida R, Yamaura T, Yashiro H, Tomita H. Resolution dependence of deep convections in a global simulation from over 10-kilometer to sub-kilometer grid spacing. Prog Earth Planet Sci. 2016;3:16.

69. Yashiro H, Kajikawa Y, Miyamoto Y, Yamaura T, Yoshida R, Tomita $\mathrm{H}$. Resolution dependence of the diurnal cycle of precipitation simulated by a global cloud-system resolving model. SOLA. 2016;12:272-6.

70. Miyakawa T, Kikuchi K. CINDY2011/DYNAMO Madden-Julian oscillation successfully reproduced in global cloud/cloud-system resolving simulations despite weak tropical wavelet power. Sci Rep. 2018;8:11664.

71. Kodama C, Yamada Y, Noda AT, et al. A 20-year climatology of a NICAM AMIP-type simulation. J Meteorol Soc Japan. 2015;93: 393-424.

72. Satoh M, Yamada Y, Sugi M, Kodama C, Noda AT. Constraint on future change in global frequency of tropical cyclones due to global warming. J Meteorol Soc Japan. 2015;93:489-500.

73. Yamada Y, Satoh M, Sugi M, Kodama C, Noda AT, Nakano M, et al. Response of tropical cyclone activity and structure to global warming in a high-resolution global nonhydrostatic model. J Clim. 2017;30:9703-24.

74. Miyakawa T, Satoh M, Miura H, Tomita H, Yashiro H, Noda AT, et al. Madden-Julian Oscillation prediction skill of a newgeneration global model demonstrated using a supercomputer. Nat Commun. 2014;5:3769.

75. Nakano M, Sawada M, Nasuno T, Satoh M. Intraseasonal variability and tropical cyclogenesis in the western North Pacific simulated by a global nonhydrostatic atmospheric model. Geophys Res Lett. 2015;42:565-71.

76. Hashino T, Satoh M, Hagihara Y, Kubota T, Matsui T, Nasuno T, et al. Evaluating cloud microphysics from NICAM against CloudSat and CALIPSO. J Geophys Res Atmos. 2013;118: 7273-92.

77. Kotsuki S, Terasaki K, Miyoshi T. GPM/DPR precipitation compared with a $3.5-\mathrm{km}$-resolution NICAM simulation. SOLA. 2014;10:204-9.

78. Miyakawa T, Yashiro H, Suzuki T, Tatebe H, Satoh M. A MaddenJulian Oscillation event remotely accelerates ocean upwelling to abruptly terminate the 1997/1998 super El Niño. Geophys Res Lett. 2017;44:9489-95. 
79. Ullrich PA, Jablonowski C, Kent J, Lauritzen PH, Nair R, Reed KA, et al. DCMIP2016: a review of non-hydrostatic dynamical core design and intercomparison of participating models. Geosci Model Dev. 2017;10:4477-509.

80. Blackburn M, Hoskins BJ. Context and aims of the Aqua-Planet Experiment. J Meteorol Soc Japan. 2013;91A:1-15.

81. Blackburn M, Williamson DL, Nakajima K, et al. The AquaPlanet Experiment (APE): CONTROL SST simulation. J Meteorol Soc Japan. 2013;91A:17-56.

82. Webb MJ, Andrews T, Bodas-Salcedo A, Bony S, Bretherton CS, Chadwick R, et al. The Cloud Feedback Model Intercomparison Project (CFMIP) contribution to CMIP6. Geosci Model Dev. 2017;10:359-84.

83. Haarsma RJ, Roberts MJ, Vidale PL, Senior CA, Bellucci A, Bao Q, et al. High Resolution Model Intercomparison Project (HighResMIP v1.0) for CMIP6. Geosci Model Dev. 2016;9:4185-208.

84. Klingaman NP, Jiang X, Xavier PK, Petch J, Waliser D, Woolnough SJ. Vertical structure and physical processes of the Madden-Julian oscillation: synthesis and summary. J Geophys Res. 2015;120:4671-89.

85. Nakano M, Wada A, Sawada M, Yoshimura H, Onishi R, Kawahara S, Sasaki W, Nasuno T, Yamaguchi M, Iriguchi T, Sugi M, and Takeuchi Y. Global $7 \mathrm{~km}$ mesh nonhydrostatic Model Intercomparison Project for improving TYphoon forecast (TYMIPG7): experimental design and preliminary results. Geosci Model Dev. 2017;10:1363-81. https://doi.org/10.5194/gmd-10-1363-2017.

86. Kinter JL, Cash B, Achuthavarier D, et al. Revolutionizing climate modeling with Project Athena: a multi-institutional, international collaboration. Bull Am Meteorol Soc. 2013;94:231-45.

87. Jung T, Miller MJ, Palmer TN, Towers P, Wedi N, Achuthavarier $D$, et al. High-resolution global climate simulations with the ECMWF model in Project Athena: experimental design, model climate, and seasonal forecast skill. J Clim. 2012;25:3155-72.

88. Stevens B. Extreme Earth: advancing global storm resolving models to usher in a new era of climate modelling and climate change science. Geophys Res Abstr. 2018;20:EGU2018-10761.

89. Orlanski I. A rational subdivision of scales for atmospheric processes. Bull Am Meteorol Soc. 1975;56:527-34.

90. Sato T, Miura H, Satoh M, Takayabu YN, Wang Y. Diurnal cycle of precipitation in the tropics simulated in a global cloud-resolving model. J Clim. 2009;22:4809-26.

91. Noda AT, Oouchi K, Satoh M, Tomita H. Quantitative assessment of diurnal variation of tropical convection simulated by a global nonhydrostatic model without cumulus parameterization. J Clim. 2012;25:5119-34.

92. Oouchi K, Noda AT, Satoh M, Wang B, Xie S-P, Takahashi HG, et al. Asian summer monsoon simulated by a global cloud-systemresolving model: diurnal to intra-seasonal variability. Geophys Res Lett. 2009;36:L11815.

93. Fudeyasu H, Wang Y, Satoh M, Nasuno T, Miura H, Yanase W. Global cloud-system-resolving model NICAM successfully simulated the lifecycles of two real tropical cyclones. Geophys Res Lett. 2008;35:L22808.

94. Fudeyasu H, Wang Y, Satoh M, Nasuno T, Miura H, Yanase W. Multiscale interactions in the life cycle of a tropical cyclone simulated in a global cloud-system-resolving model. Part II: systemscale and mesoscale processes. Mon Weather Rev. 2010;138: 4305-27.

95. Roh W, Satoh M, Nasuno T. Improvement of a cloud microphysics scheme for a global nonhydrostatic model using TRMM and a satellite simulator. J Atmos Sci. 2017;74:167-84.

96. Seiki T, Kodama C, Noda AT, Satoh M. Improvement in global cloud-system-resolving simulations by using a double-moment bulk cloud microphysics scheme. J Clim. 2015;28:2405-19.

97. Kubokawa H, Fujiwara M, Nasuno T, Satoh M. Analysis of the tropical tropopause layer using the Nonhydrostatic Icosahedral
Atmospheric Model (NICAM): aqua planet experiments. J Geophys Res. 2010;115:D08102.

98. Kubokawa H, Fujiwara M, Nasuno T, Miura H, Yamamoto M, Satoh M. Analysis of the tropical tropopause layer using the Nonhydrostatic Icosahedral Atmospheric Model (NICAM): 2. An experiment under the atmospheric conditions of December 2006 to January 2007. J Geophys Res. 2012;117:D17114.

99. Kubokawa H, Satoh M, Suzuki J, Fujiwara M. Influence of topography on temperature variations in the tropical tropopause layer. J Geophys Res Atmos. 2016;121:11556-74.

100. Shibuya R, Sato K, Tsutsumi M, Sato T, Tomikawa Y, Nishimura $\mathrm{K}$, et al. Quasi-12 h inertia-gravity waves in the lower mesosphere observed by the PANSY radar at Syowa Station $\left(39.6^{\circ} \mathrm{E}, 69.0^{\circ} \mathrm{S}\right)$. Atmos Chem Phys. 2017;17:6455-76.

101. Shibuya R, Sato K. A study of the dynamical characteristics of inertia-gravity waves in the Antarctic mesosphere combining the PANSY radar and a non-hydrostatic general circulation model. Atmos Chem Phys. 2019;19:3395-415.

102. Terasaki K, Tanaka HL, Satoh M. Characteristics of the kinetic energy spectrum of NICAM model atmosphere. SOLA. 2009;5: 180-3.

103. Skamarock WC, Park S-H, Klemp JB, Snyder C. Atmospheric kinetic energy spectra from global high-resolution nonhydrostatic simulations. J Atmos Sci. 2014;71:4369-81.

104. Bessho K, Date K, Hayashi M, et al. An introduction to Himawari8/9-Japan's new-generation geostationary meteorological satellites. J Meteorol Soc Japan. 2016;94:151-83.

105. Masunaga H, Satoh M, Miura H. A joint satellite and global cloudresolving model analysis of a Madden-Julian oscillation event: model diagnosis. J Geophys Res. 2008;113:D17210.

106. Roh W, Satoh M. Evaluation of precipitating hydrometeor parameterizations in a single-moment bulk microphysics scheme for deep convective systems over the tropical central Pacific. J Atmos Sci. 2014;71:2654-73.

107. Inoue T, Satoh M, Miura H, Mapes B. Characteristics of cloud size of deep convection simulated by a global cloud resolving model over the western tropical Pacific. J Meteorol Soc Japan. 2008;86A: $1-15$.

108. Seiki T, Satoh M, Tomita H, Nakajima T. Simultaneous evaluation of ice cloud microphysics and non-sphericity of the cloud optical properties using hydrometeor video sonde and radiometer sonde in-situ observations. J Geophys Res Atmos. 2014;119:6681-701.

109. McCarty W, Errico RM, Gelaro R. Cloud coverage in the joint OSSE nature run. Mon Weather Rev. 2012;140:1863-71.

110. Stevens B, Lenschow DH. Observations, experiments, and large eddy simulation. Bull Am Meteorol Soc. 2001;82:283-94.

111. Miyakawa T, Takayabu YN, Nasuno T, Miura H, Satoh M, Moncrieff MW. Convective momentum transport by rainbands within a Madden-Julian oscillation in a global nonhydrostatic model with explicit deep convective processes. Part I: methodology and general results. J Atmos Sci. 2012;69:1317-38.

112. Tomita H. A stretched icosahedral grid by a new grid transformation. J Meteor Soc Japan. 2008;86A:107-19.

113. Uchida J, Mori M, Nakamura H, Satoh M, Suzuki K, Nakajima T. Error and energy budget analysis of a nonhydrostatic stretchedgrid global atmospheric model. Mon Weather Rev. 2016;144: 1423-47.

114. Uchida J, Mori M, Hara M, Satoh M, Goto D, Kataoka T, et al. Impact of lateral boundary errors on the simulation of clouds with a nonhydrostatic regional climate model. Mon Weather Rev. 2017;145:5059-82.

115. Ohno T, Satoh M. Roles of cloud microphysics on cloud responses to sea surface temperatures in radiative-convective equilibrium experiments using a high-resolution global nonhydrostatic model. J Adv Model Earth Syst. 2018;10:1970-89. 
116. Heinze R, Dipankar A, Henken CC, et al. Large-eddy simulations over Germany using ICON: a comprehensive evaluation. Q J R Meteorol Soc. 2016;143:69-100.

117. Sato Y, Miura H, Yashiro H, Goto D, Takemura T, Tomita H, et al. Unrealistically pristine air in the Arctic produced by current global scale models. Sci Rep. 2016;6:26561.

118. Yashiro H, Terai M, Yoshida R, Iga S-I, Minami K, Tomita H. Performance analysis and optimization of nonhydrostatic icosahedral atmospheric model (NICAM) on the $\mathrm{K}$ computer and TSUBAME2.5. PASC 2016 - Proc Platf Adv Sci Comput Conf. 2016;1-8

119. Yashiro H, Terasaki K, Miyoshi T, Tomita H. Performance evaluation of a throughput-aware framework for ensemble data assimilation: the case of NICAM-LETKF. Geosci Model Dev. 2016;9: 2293-300.

120. Klein R, Achatz U, Bresch D, Knio OM, Smolarkiewicz PK. Regime of validity of soundproof atmospheric flow models. J Atmos Sci. 2010;67:3226-37.

121. Kurowski MJ, Grabowski WW, Smolarkiewicz PK. Anelastic and compressible simulation of moist deep convection. J Atmos Sci. 2014;71:3767-87.

122. Kurowski MJ, Grabowski WW, Smolarkiewicz PK. Anelastic and compressible simulation of moist dynamics at planetary scales. J Atmos Sci. 2015;72:3975-95.

123. Eliassen A. The quasi-static equations of motion with pressure as independent variable. Geofys Publ. 1949;17:1-43.

124. Boucher O, Randall D, Artaxo P, et al. Clouds and aerosols. Climate Change 2013 the Physical Science Basis: Working Group I Contribution to the Fifth Assessment Report of the Intergovernmental Panel on Climate Change. 2013;9781107057: 571-658.

125. Lin J-L. The double-ITCZ problem in IPCC AR4 coupled GCMs: ocean-atmosphere feedback analysis. J Clim. 2007;20:4497-525.

126. Bellucci A, Gualdi S, Navarra A. The double-ITCZ syndrome in coupled general circulation models: the role of large-scale vertical circulation regimes. J Clim. 2010;23:1127-45.

127. Oueslati B, Bellon G. The double ITCZ bias in CMIP5 models: interaction between SST, large-scale circulation and precipitation. Clim Dyn. 2015;44:585-607.
128. Kodama C, Noda AT, Satoh M. An assessment of the cloud signals simulated by NICAM using ISCCP, CALIPSO, and CloudSat satellite simulators. J Geophys Res. 2012;117:D12210.

129. Becker T, Stevens B, Hohenegger C. Imprint of the convective parameterization and sea-surface temperature on large-scale convective self-aggregation. J Adv Model Earth Syst. 2017;9:1488-505.

130. Crueger T, Giorgetta MA, Brokopf R, Esch M, Fiedler S, Hohenegger $\mathrm{C}$, et al. ICON-A, the atmosphere component of the ICON Earth system model: II. Model evaluation. J Adv Model Earth Syst. 2018;10:1638-62.

131. Harris LM, Lin S-J. A two-way nested global-regional dynamical core on the cubed-sphere grid. Mon Weather Rev. 2013;141:283-306.

132. Lin S-J, Rood RB. An explicit flux-form semi-Lagrangian shallow-water model on the sphere. Q J R Meteorol Soc. 1997;123:2477-98.

133. Lin S-J. A finite-volume integration method for computing pressure gradient force in general vertical coordinates. Q J R Meteorol Soc. 1997;123:1749-62.

134. Lin S-J, Rood RB. Multidimensional flux-form semi-Lagrangian transport schemes. Mon Weather Rev. 1996;124:2046-70.

135. Chen JH, Lin SJ. Seasonal predictions of tropical cyclones using a 25km-resolution general circulation model. J Clim. 2013;26:380-98.

136. Wedi N. Increasing horizontal resolution in numerical weather prediction and climate simulations: illusion or panacea? Philos Trans R Soc A Math Phys Eng Sci. 2014;372:20130289.

137. Düben PD, Palmer TN. Benchmark tests for numerical weather forecasts on inexact hardware. Mon Weather Rev. 2014;142: 3809-29.

138. Váňa F, Düben $\mathrm{P}$, Lang $\mathrm{S}$, Palmer T, Leutbecher M, Salmond D, et al. Single precision in weather forecasting models: an evaluation with the IFS. Mon Weather Rev. 2016;145:495-502.

139. Smolarkiewicz PK, Kühnlein C, Wedi NP. A consistent framework for discrete integrations of soundproof and compressible PDEs of atmospheric dynamics. J Comput Phys. 2014;263:185-205.

140. Kühnlein C, Smolarkiewicz PK. An unstructured-mesh finite-volume MPDATA for compressible atmospheric dynamics. J Comput Phys. 2017;334:16-30.

Publisher's Note Springer Nature remains neutral with regard to jurisdictional claims in published maps and institutional affiliations. 